\title{
Prospects of performing multiple-country comparison of dairy sires for countries not participating in Interbull international genetic evaluations
}

\author{
A. Loberg ${ }^{1,2 \#}$, H. Jorjani ${ }^{1,2}$, W.F. Fikse ${ }^{2}$ \\ ${ }^{1}$ Interbull Centre \\ ${ }^{2}$ Department of Animal Breeding and Genetics, SLU, Uppsala, Sweden
}

\begin{abstract}
International trade with genetic material has lead to the foundation of Interbull, an international organization that performs international evaluations of dairy bulls, enabling countries to obtain breeding values of foreign bulls on their on scale. Not all countries have the possibility to participate in the evaluations with their own national breeding values. The aim of this study was to find an alternative method that does not require national breeding values. Argentina was used as a representative of countries without national breeding values. For this study national breeding values for 909 Argentinean bulls were available; these records were used in a normal Interbull international evaluation and used as reference. The alternative method considers Argentinean bulls as unrecorded, but correlated to bulls in other countries. This method was used with seven different correlation matrices, giving seven alternatives to compare with the reference. Results showed correlation between reference and the alternative methods ranging between 0.926 and 0.973 , and loss in genetic gain between $2.82 \%$ and $11.9 \%$. This means that this alternative method could be used for countries that do not have national breeding values to submit for international evaluations.
\end{abstract}

Keywords: Dairy, Developing country, GxE, International genetic evaluation

" Corresponding author. E-mail: Loberg.Anne@hgen.slu.se

\section{Introduction}

To increase the transparency of the market for genetic material, Interbull was founded in 1983. Since then the organization has grown substantially and distributes today international breeding values for 27 countries, six breeds and six trait groups. This international evaluation service enables fair comparisons of dairy bulls across country borders and is a good tool when choosing animals to import. Countries not participating in Interbull international evaluations cannot make accurate choices when they import semen and bulls, due to the lack of estimated breeding values (EBV) of foreign bulls adjusted for their country and production environment. This, however, does not mean that there is no trade. Many non-member countries import semen from large international companies with the aim of improving the national milk production.

The problem when selecting bulls from another country is that bulls perform differently in different production environments. This means that ranking amongst bulls can differ between countries. Reasons for re-ranking are genotype by environment interaction, differences in trait definitions and differences in the national analyses (Powell \& VanRaden, 2002). Re-ranking of bulls between countries is seen in every international evaluation performed by Interbull and also in scientific studies (Cienfuegos-Rivas et al., 1999; Costa et al., 2000). In a study by Ojango \& Pollott (2002) they showed that selecting bulls on the British scale for use in Kenya did not give the same response in Kenya as in England.

Mark et al. (2006a) proposed a method to predict international EBV for a non-measured trait, using records for correlated traits. Mark et al. (2006a) illustrated the method with clinical mastitis in the Unite States as the unrecorded trait and somatic cell count and mastitis in other countries as the correlated recorded traits. In this study we exemplified the extension of the model by taking, as an example the breeding value for milk yield in Argentina as the unrecorded trait and breeding value for milk yield in other countries as the recorded traits.

The aim of this study is to examine if it is possible to obtain international EBVs for a country without using their national genetic merit. Argentina will be the country representing countries that do not participate in Interbull international genetic evaluations. 


\section{Materials and Methods}

Data for this study consisted of national breeding values for milk yield for 100642 Holstein bulls submitted for the August 2006 routine Interbull evaluation and for 909 Holstein bulls used in Argentina.

A reference situation was created by including the data from Argentina in normal Interbull evaluation, estimating genetic correlations amongst countries with an EM-REML algorithm and international breeding values with MACE (Schaeffer, 1994). The international breeding values obtained were used as reference to compare with the results from the alternative methods.

According to this method EBV for the recorded traits are first calculated with MACE. These values are then combined into EBV for the non-recorded trait by using the following method:

$$
\mathrm{U}_{\mathrm{i}^{+}}=\mathrm{g}^{\prime} \mathrm{V}^{-1} \hat{\mathrm{u}}_{\mathrm{i}}
$$

where; $\hat{\mathrm{u}}_{\mathrm{i}}=$ the vector of MACE solutions for recorded traits, $\mathrm{i}=$ recorded traits, $\mathrm{i}+=$ a non-measured trait, $\mathrm{g}=\mathrm{a}$ vector containing correlations between the recorded and non-recorded traits, $\mathrm{V}=$ the (co)variance matrix among the predicted international breeding values $\left(\mathrm{u}_{\mathrm{i}}\right)$ from MACE (Mark et al., 2006a).

For the Interbull evaluations correlations amongst countries are estimated with an EM-REML algorithm, which requires national breeding values. Mark et al. (2006b) developed an alternative approach to obtain genetic correlations for non-recorded traits. With this method genetic correlations are estimated using a multiple regression method:

$$
\begin{aligned}
& \text { Prior: } \mathrm{r}^{5}=\mu+\mathrm{b}_{1} \text { milk }+\mathrm{b}_{2} \text { grass }+\mathrm{b}_{3} \text { wind }+\mathrm{b}_{4} \text { temp }+\mathrm{b}_{5} \mathrm{~h}^{2}+\mathrm{b}_{6} \text { par }+\mathrm{b}_{7} \mathrm{CB} \\
& \text { Prior }+: \mathrm{r}^{5}=\mu^{\prime}+\mathrm{b}_{1} \text { milk }+\mathrm{b}_{2} \text { grass }+\mathrm{b}_{3} \text { wind }+\mathrm{b}_{4} \text { temp }
\end{aligned}
$$

where: milk $=$ ratio for milk yield, grass $=$ grazing, wind $=$ ratio for average wind speed, temp $=$ ratio for average temperature, $h^{2}=$ ratio for heritability, par $=$ ratio for number of parities, $C B=$ ratio for number of common bulls between two countries. Variables are either expressed as ratios or binary variables. For continuous values such as milk, temperature or wind, a ratio was calculated, putting the highest value in the denominator. This gives a value between one and zero; the more similar two countries are the higher the value. For class variables the variable was set as one or zero, 1 if both countries belonged to the same group, for example grazing countries. Method [3] is a modification of Method [2] where variables not directly associated with $\mathrm{G} \times \mathrm{E}$ are excluded. These variables are included in $\mu$ ' and are fixed at their maximum values (Mark et al., 2006b).

Table 1 Different alternatives used to predict international genetic merits

\begin{tabular}{ccccc}
\hline Alternative & $\mathrm{r}_{\mathrm{G}}{ }^{\mathrm{a}}$ & $\mathrm{EBV}^{\mathrm{b}}$ & Data $^{\mathrm{c}}$ & $\mathrm{N}^{\mathrm{e}}$ \\
\hline ref & EM-REML & MACE & 25 countries & 100,895 \\
REML & EM-REML & Model [1] & 24 countries & 100,642 \\
prior & Eq. [2] & Model [1] & 24 countries & 100,642 \\
prior + & Eq. [3] & Model [1] & 24 countries & 100,642 \\
0.5 & 0.5 & Model [1] & 24 countries & 100,642 \\
0.6 & 0.6 & Model [1] & 24 countries & 100,642 \\
0.7 & 0.7 & Model [1] & 24 countries & 100,642 \\
0.8 & 0.8 & Model [1] & 24 countries & 100,642
\end{tabular}

\footnotetext{
${ }^{\mathrm{a}}$ Method of estimating correlation or the value of the correlation.

${ }^{\mathrm{b}}$ The method used for estimating international breeding values.

${ }^{\text {c }}$ Number of countries included for estimation of international breeding values.

${ }^{\mathrm{e}}$ Number of bulls included in each alternative.
} 
Seven sets of international breeding values were estimated with Method [1], using different vectors of correlations between Argentina and the other countries. For the first alternative the genetic correlations were those obtained for the reference situation (i.e. estimated using an EM-REML algorithm). Two sets of genetic correlations were created by using Methods [2] and [3]. Four sets of genetic correlations were created with the arbitrary values $0.5,0.6,0.7$ and 0.8 .

Comparisons between the different datasets (Table 1) were performed using SAS (2004).

\section{Results and Discussion}

The correlation between breeding values for the reference and the alternatives range between 0.926 and 0.973 , the highest correlations were with alternative REML and prior+ (Table 2). Between the alternatives with genetic correlation vector of 0.5 to 0.8 the correlations between breeding values were close to one, indicating that the size of correlation did not have an impact on the result.

Table 2 Pearson correlations of Argentinian EBV from different alternatives

\begin{tabular}{ccccccccc}
\hline Alternative & ref & REML & prior & prior + & 0.5 & 0.6 & 0.7 & 0.8 \\
\hline ref & \multirow{2}{*}{1} & 0.973 & 0.925 & 0.944 & 0.926 & 0.926 & 0.926 & 0.926 \\
REML & & 1 & 0.946 & 0.962 & 0.952 & 0.952 & 0.952 & 0.952 \\
prior & & & 1 & 0.987 & 0.969 & 0.969 & 0.969 & 0.969 \\
prior+ & & & & 1 & 0.992 & 0.992 & 0.992 & 0.992 \\
0.5 & & & & & 1 & $1^{*}$ & $1^{*}$ & $1^{*}$ \\
0.6 & & & & & & 1 & $1^{*}$ & $1^{*}$ \\
0.7 & & & & & & & & 1 \\
0.8 & & & & & & & & 1 \\
\end{tabular}

$1 *>0.99998$

To compare the EBV in the different alternatives to see how the alternatives influence selection, the mean EBV for the different alternatives was calculated on the references scale (Table 3). The smallest deviation from the reference situation was obtained when choosing the 100 best bulls based on the EBV values calculated with genetic correlations obtained with EM-REML and the largest deviation was obtained with bulls ranked from the prior. The mean EBV calculated when bulls were ranked based on EBV calculated with genetic correlations $0.5 ; 0.6$; 0.7 and 0.8 all showed very similar values.

Table 3 Mean Argentinian estimated breeding values for milk for the top 100 bulls in the different alternatives

\begin{tabular}{ccc}
\hline Alternative & $\mathrm{EBV}_{\mathrm{rG}}{ }^{\mathrm{a}}$ & Deviation (\%) \\
\hline ref & 451.54 & - \\
REML & 438.79 & 2.82 \\
prior & 397.99 & 11.9 \\
prior + & 417.10 & 7.6 \\
0.5 & 402.13 & 10.9 \\
0.6 & 402.69 & 10.8 \\
0.7 & 402.69 & 10.8 \\
0.8 & 403.06 & 10.7
\end{tabular}

${ }^{\text {a }}$ Mean value of EBVs for Argentina when the top 100 bulls are selected according to the different alternatives.

Number of common bulls among the top 100 between the reference situation and the alternatives ranged between 67 (REML) and 37 (prior); the highest number of co-selected bulls for the alternatives with 
another correlation vector than the reference, was 56 (prior+). Between the alternatives with correlation 0.6 and 0.7, all top 100 bulls were co-selected and between the all the other alternatives with fixed correlation value there were 98 or 99 co-selected. This could explain the similarity of results for these alternatives, as seen in Table 3. All alternatives included, with few exceptions, bulls from the same country as the reference in the top 100 bull list (results not shown).

\section{Conclusions}

International breeding values could be estimated for bulls in a country without own national breeding values. The results showed high correlations with the reference situation where national evaluation results were available and many bulls would therefore be correctly selected. The method is easy to use and could be used to give an indication of international breeding values for countries not participating in Interbull evaluations.

\section{References}

Cienfuegos-Rivas, E.G., Oltenacu, P.A., Blake, R.W., Schwager, S.J., Castillo-Juarez, H. \& Ruiz, F.J., 1999. Interaction between milk yield of Holstein cows in Mexico and the United States. J. Dairy Sci. 82, 2218-2223.

Costa, C.N., Blake, R.W., Pollak, E.J., Oltenacu, P.A., Quaas, R.L. \& Searle, S.R., 2000. Genetic analysis of Holstein cattle populations in Brazil and the United States. J. Dairy Sci. 83, 2963-2974.

Mark, T., Fikse, F.W., Sullivan, P.G. \& VanRaden, P.M., 2006a. Prediction of international breeding values for non-measured traits: Application to clinical mastitis 8th World Congress on Genetic Applied to Livestock Production, Belo Horizonte, MG, Brazil.

Mark, T., Sullivan, P.G., Fikse, F.W. \& VanRaden, P.M., 2006b. Prior genetic correlations and nonmeasured traits. Department of Animal Breeding and Genetics, Uppsala, Sweden.

Ojango, J.M.K. \& Pollott, G.E., 2002. The relationship between Holstein bull breeding values for milk yield derived in both the UK and Kenya. Livest. Prod. Sci. 74, 1-12.

Powell, R.L. \& VanRaden, P.M., 2002. International dairy bull evaluations expressed on national, subglobal and global scales. J. Dairy Sci. 85, 1863-1868.

SAS, 2004. SAS Institute Inc. Release 9.1.2. SAS Institute Inc., Cary, N.C., USA.

Schaeffer, L.R., 1994. Multiple-Country comparison of dairy sires. J. Dairy Sci. 77, 2671-2678. 